\title{
LA VIOLENCIA ECONÓMICA Y/O PATRIMONIAL CONTRA LAS MUJERES EN EL ÁMBITO FAMILIAR
}

\author{
INTRA-FAMILY ECONOMIC AND PATRIMONIAL VIOLENCE AGAINST \\ WOMEN
}

Ocner Córdova López ${ }^{1}$

\section{Resumen}

En el presente artículo analizamos el nuevo tipo de violencia contra las mujeres y los integrantes del grupo familiar, esto es la violencia económica y patrimonial en el ámbito familiar, la misma que ha sido recientemente regulada en la Ley $\mathrm{N}^{\circ} 30364$ - Ley para prevenir, sancionar y erradicar la violencia contra las mujeres y los integrantes del grupo familiar. Se analiza su definición, sus características, la importancia de prevenir, sancionar y erradicar este tipo de violencia, la forma de cómo ha sido regulada en otros países cercanos al nuestro, los diferentes supuestos y casos típicos de violencia económica y patrimonial y sus diferencias, y la importancia de erradicar este tipo de violencia en el ámbito familiar.

Palabras clave: violencia familiar, violencia económica, violencia patrimonial.

\section{Abstract:}

In this article we analyze the new type of violence against women and other family members, i.e. intra-family economic and patrimonial violence, which has recently been regulated by Law No. 30364 - Law to prevent, punish, and eradicate violence against women and other family members. The paper analyzes the definition of the concept, its characteristics, the importance of preventing, punishing, and eradicating this type of violence, the way it has been regulated in other neighboring countries, the different assumptions and typical cases of economic and patrimonial violence, their differences, and the importance of eradicating this type of violence in the family.

Keywords : family violence, economic family, patrimonial violence.

Magistrado de la Corte Superior de Justicia de Lima Este -Poder Judicial del Perú. Magister en Derecho Civil; Juez Titular del Segundo Juzgado Civil de San Juan de Lurigancho. 


\section{INTRODUCCIÓN}

La violencia física, sexual y/o psicológica no son los únicos tipos de violencia que sufren las mujeres o los integrantes del grupo familiar. Cuando el agresor controla todos los ingresos del hogar, independientemente de quien los haya adquirido, cuando manipula el dinero o solo se lo da a "cuenta gotas" a la víctima para el sostenimiento del hogar, cuando el agresor reclama constantemente en qué lo ha gastado y como lo ha gastado o le impide a la víctima tener un trabajo propio que pueda generarle sus ingresos, estamos frente a un tipo de violencia de género denominada: violencia económica. Asimismo, cuando el agresor esconde los objetos de valor de la víctima o los documentos personales o no le permite disponer de los bienes comunes, se configura la violencia patrimonial. En este tipo de violencia también observamos que el agresor utiliza diferentes estrategias para persuadir a la víctima de que le entregue el dinero producto de su trabajo y/o de que se lo de todo a él para controlarlo y administrarlo; también ocurre que si el agresor trabaja no le dice a la víctima a cuánto ascienden sus ingresos.

La violencia económica y patrimonial dentro del ámbito familiar, si bien son dos formas distintas de ejercer violencia en contra de la mujer (generalmente), tienen una característica común: se ejercen por el agresor de una manera muy sutil e imperceptible al inicio; por ello, se considera que es un poco difícil de identificar, pero a medida que la mujer va aceptando o soportando este tipo de violencia, la agresión va aumentando, se torna insostenible y puede escalar, casi siempre ocurre, en violencia física y psicológica, y es allí cuando recién al denunciarse la identificamos, la sancionamos y dictamos medidas de protección.

La acreditación de la existencia de la violencia económica y patrimonial, a diferencia de la violencia física y psicológica en donde se acredita fácilmente con un certificado médico o dictamen pericial, es mucho más difícil, pues no existe un certificado médico o psicológico que lo acredite como tal. Muchas veces detectamos la existencia de violencia económica o patrimonial en la víctima cuando se ha llegado a la violencia física y psicológica; por tanto, la tarea del Estado, jueces, fiscales, policía nacional y demás personal involucrado debe también comprender la identificación oportuna de la violencia económica y patrimonial y su correspondiente sanción inmediata dictando la medida de protección más adecuada, antes de que se llegue a la violencia física y psicológica. 


\section{DEFINICIÓN DE VIOLENCIA ECONÓMICA Y PATRIMONIAL}

Una definición que resulta importante tomar en consideración a efectos de definir a la violencia económica y patrimonial, desde mi punto de vista, es la establecida por la Ley Especial Integral para una Vida Libre de Violencia Contra Las Mujeres, aprobada mediante Decreto 520 de 2011, otorgado por la Asamblea Legislativa de la República de El Salvador ${ }^{2}$. Esta disposición normativa define separadamente de manera clara y precisa a la violencia económica y patrimonial en su artículo $9^{\circ}$, de la siguiente manera:

“a) Violencia Económica: Es toda acción u omisión de la persona agresora, que afecta la supervivencia económica de la mujer, la cual se manifiesta a través de actos encaminados a limitar, controlar o impedir el ingreso de sus percepciones económicas. (...)

e) Violencia Patrimonial: Son las acciones, omisiones o conductas que afectan la libre disposición del patrimonio de la mujer; incluyéndose los daños a los bienes comunes o propios mediante la transformación, sustracción, destrucción, distracción, daño, pérdida, limitación, retención de objetos, documentos personales, bienes, valores y derechos patrimoniales. En consecuencia, serán nulos los actos de alzamiento, simulación de enajenación de los bienes muebles o inmuebles; cualquiera que sea el régimen patrimonial del matrimonio, incluyéndose el de la unión no matrimonial".

Para la República de El Salvador, la violencia económica se manifiesta a través de actos que tienen como finalidad limitar, controlar o impedir el ingreso de sus percepciones económicas. Si el agresor impide a la víctima que trabaje fuera de casa, si controla sus ingresos o la forma como gasta el dinero obtenido, está violentando económicamente a su pareja.

De igual modo, si el agresor destruye o sustrae objetos valiosos y/o importantes para la víctima, está cometiendo violencia patrimonial; asimismo, si simula venta de bienes muebles o inmuebles, cualquiera que sea el régimen patrimonial del matrimonio que perjudiquen a la víctima, dichos actos serán nulos por constituir violencia patrimonial.

De otro lado, de manera más simple se ha definido a la violencia económica como: "todo acto de fuerza o de poder ejercido contra las mujeres y que vulneran sus derechos económicos" (Núñez, 2009, p.3); o también como: "Una serie de mecanismos de control y vigilancia sobre el comportamiento de las mujeres en relación al uso y distribución del dinero, junto con la amenaza constante de no proveer recursos económicos" (Medina, 2013, p.107).

Disponible en: http:/ /www.acnur.org/t3 / fileadmin/Documentos/BDL/2014/9509.pdf. 
Para otros, la violencia patrimonial puede ser considerada una subcategoría de la violencia psicológica, especialmente porque genera los mismos perjuicios en la víctima. Sin embargo, la diferencia entre ambas radica en que el control patrimonial implica para la víctima, finalmente, dependencia del victimario. Se pretende aislar a la víctima de otras personas, generando un círculo de relación con el abusador. (Trufello, 2017, p. 3).

En efecto, si el agresor daña los bienes o pertenencias de la víctima, le esconde los documentos personales, pasaporte, visa, certificados o diplomas de estudio, o dispone de los bienes sin el consentimiento de la mujer, está ejerciendo violencia patrimonial en contra de ella. Es probable que algunos piensen que esto no es violencia, ya que no hay golpes, ni gritos de por medio, pero son acciones que lastiman y perjudican el derecho a vivir una vida digna, en consecuencia, sí es violencia.

\section{LA VIOLENCIA ECONÓMICA Y PATRIMONIAL UN POCO IMPERCEPTIBLE AL INICIO PERO IGUAL DE DAÑINA}

Muchas veces la víctima (casi siempre la mujer) cree que ciertos actos que constituyen violencia económica o patrimonial, como por ejemplo, que el agresor no le permita trabajar o que le reclame constantemente sobre cómo gasta el dinero de la semana o incluso que le esconda sus pertenencias por un tiempo, los considera como "normales" o los acepta en la creencia que dichos actos no constituyen violencia y que no los podría denunciar. Existe un estereotipo de género en las víctimas de violencia económica y patrimonial, pues, con la mejor buena fe piensan que siempre fue así y consideran que es "obligación del hombre" proveer y "deber de la mujer" depender; incluso cuando una mujer realiza trabajos fuera del hogar creen que lo hacen "para ayudar" a su cónyuge o conviviente y no por un derecho propio.

Habíamos dicho ya, que una de las características de la violencia económica y patrimonial es que se configura al inicio de una manera muy sutil, desapercibida y encubierta, pero a medida que se le va aceptando por la víctima, esta violencia se va haciendo sentir y se va incrementando de manera gradual, hasta hacerse insoportable; por ejemplo, cuando el agresor "proveedor" deja de manera intencional el dinero exacto para el gasto diario, "ni un sol más", y controla los gastos que realiza, exigiéndole constantemente que le dé cuenta en qué lo ha gastado y cómo lo ha gastado; cuando no le permite trabajar fuera del hogar para generar sus propios ingresos o si la víctima consigue un trabajo, el agresor le quita el dinero para administrarlo solo él; luego se incrementa la violencia económica cuando el agresor no le deja dinero para la alimentación diaria para ella y sus propios hijos; y es que, 
cuando la víctima empieza a protestar y a reclamar, porque ya no soporta más la situación que, el agresor recurre a la violencia física generando también daños psicológicos a la víctima.

La violencia económica y patrimonial suele ser desestimada o aceptada por la víctima en un inicio, quien no le da importancia a los manejos controladores del agresor, tal vez por desconocimiento que este tipo de abuso económico sí puede ser denunciado o quizás, porque debido a la cultura machista o un estereotipo de género, lo considera como "algo normal" pensando que "así debe ser" o que "siempre fue así"; "las víctimas creen que su problema no es lo suficientemente serio o dañino como para intentar detenerlo o denunciarlo" (Diez Sara, 2012). Sin embargo, este tipo de violencia económica y patrimonial generalmente no queda ahí, sino que, cuando la víctima protesta o reclama, cuando se niega a seguir soportando y rechaza el abuso económico o patrimonial de su pareja, obtiene como consecuencia la violencia física y psicológica; es ahí cuando recién decide denunciar al agresor. En efecto, existen muchos casos de violencia física y psicológica que tienen su origen en la violencia económica y patrimonial; por ello es de suma importancia que la mujer víctima de este tipo de violencia denuncie de forma inmediata el abuso económico y/o patrimonial del que está siendo objeto y que tanto la Policía Nacional como los jueces y fiscales reciban este tipo de denuncia sin necesidad de la existencia de certificado médico o examen psicológico, dictando de forma inmediata la medida de protección más adecuada.

Sin duda alguna, constituye un avance significativo que la Ley $\mathrm{N}^{\circ}$ 30364, a diferencia de su antecesora la Ley $N^{\circ} 26260$, Ley de Protección frente a la Violencia Familiar, ampare este nuevo tipo de violencia contra la mujer; pero no es que se trate de una nueva violencia, la violencia económica y patrimonial es muy antigua, siempre ha existido, sino que es recién que nuestra legislación nacional la ha contemplado.

Ahora, solo falta que tanto las víctimas de este tipo de violencia, como la Policía Nacional del Perú (que son la primera entidad a donde recurren las víctimas generalmente) y los operadores de justicia (jueces y fiscales) conozcamos bien cuándo estamos ante un caso de violencia económica o patrimonial, sin que aún exista violencia física y/o psicológica, a efectos de dar una debida atención y protección a la víctima, toda vez que, si no conocemos esta situación, corremos el riesgo de dejar desamparada a la víctima y con ello perpetuar y prolongar este tipo de violencia contra la mujer. 
Lo común es que llegue a nuestros despachos denuncias de violencia familiar solo por violencia física, psicológica y sexual. En pocas ocasiones hemos tenido la oportunidad de observar algunos casos puros de violencia económica o patrimonial. Es muy escasa la denuncia solo por violencia económica y patrimonial, la mayoría está relacionada con la violencia física y psicológica, es ahí cuando recién se detecta. Ante esta escasa denuncia por violencia económica y/o patrimonial corresponde preguntarse al respecto:¿será tal vez porque las víctimas de este tipo de violencia desconocen que estos actos también constituyen un tipo violencia familiar? ¿Será que en las comisarías de la Policía Nacional del Perú no se reciben las denuncias de este tipo por considerar que no es violencia familiar? ¿Será que los operadores de justicia no le damos mucha importancia o desconocemos la existencia de este tipo de violencia y no otorgamos las medidas de protección adecuadas? Sea cual fuere la respuesta, lo importantes es que reconozcamos y tomemos conciencia que este tipo de violencia contra la mujer es muy frecuente, que si bien no es muy perceptible o visible en forma inmediata-como en el caso de violencia física y psicológicasin embargo, también constituye un tipo de violencia contra la mujer, que la disminuye, la limita, la restringe, la mutila y aniquila en su independencia como mujer. Pese a que sus efectos resultan menos visibles que los dejados por la violencia física, psicológica o sexual, sin embargo, la violencia económica y patrimonial resulta ser mucho más habitual y frecuente para un mayor número de mujeres generalmente, pero es igual de nociva. Siendo por ello una enorme responsabilidad del Estado, representado por todos los involucrados, jueces, fiscales, Policía Nacional, etc., luchar contra este tipo de violencia, detectándola y sancionándola antes que se desemboque en una violencia física y psicológica.

\section{LA VIOLENCIA ECONÓMICA Y PATRIMONIAL EN LAS DIFERENTES LEGISLACIONES}

Si bien la violencia económica y patrimonial, como un tipo de violencia familiar, es reconocida en nuestro país por vez primera con la Ley $\mathrm{N}^{\circ} 30364$ (publicada el 22/11/2015), sin embargo, este tipo de violencia contra la mujer era ya reconocida y regulada por otras legislaciones de países como Costa Rica con la promulgación de la Ley Contra la Violencia Doméstica, Ley $\mathrm{N}^{\circ} 7586^{3}$, de fecha 10 de abril de 1996, que en su artículo $2^{\circ}$ literal e) reconocía expresamente como un tipo de violencia contra la mujer, la violencia patrimonial. Así, la definía como: "Acción u omisión que implica daño, pérdida, transformación, sustracción, destrucción, retención o distracción de objetos, instrumentos de trabajo, documentos personales, bienes, valores, derechos o recursos económicos destinados a satisfacer las necesidades de alguna de las personas mencionadas en el inciso a) anterior".

Disponible en: http:/ /www.sipi.siteal.iipe.unesco.org 
Otros países que reconocieron con anticipación al nuestro la existencia de una violencia económica y/o patrimonial contra la mujer son los siguientes: Honduras a través de la "Ley Contra la Violencia Doméstica", promulgada en septiembre de 1997 (y entró en vigencia en febrero de 1998), esta norma en su artículo $5^{\circ}$ numeral 4) reconocía y regulaba la violencia patrimonial y económica contra la mujer; Panamá con la Ley $\mathrm{N}^{\circ} 38$ del 10 de julio de 2001, "Ley que reforma y adiciona artículos al Código Penal y Judicial, sobre Violencia Doméstica y Maltrato al Niño, Niña y Adolescente", regulaba en su artículo $2^{\circ}$ numeral 10, la violencia económica contra la mujer; México, desde el 01 de febrero de 2007, con la promulgación de la "Ley General de Acceso a la Mujeres a un Vida Libre de Violencia", se reconoció la existencia de estos tipos de violencia en el artículo $6^{\circ}$ numeral III y IV (violencia económica y patrimonial); Uruguay, mediante la Ley $\mathrm{N}^{\circ} 17.514$ de Violencia Doméstica, de fecha 09 de julio de 2002 reconoce como un tipo de violencia contra la mujer la violencia patrimonial; Argentina, mediante la Ley 26.485, denominada "Ley de protección integral para prevenir, sancionar y erradicar la violencia contra las mujeres en los ámbitos en que desarrollen sus relaciones interpersonales", promulgada el 01 de abril de 2009, en su artículo 5, numeral 4, considera como un tipo de violencia familiar la económica y patrimonial; El Salvador a través del Decreto 520 denominado "Ley Especial Integral para una vida libre de violencia para las mujeres", publicada con fecha 04 de enero de 2011, en su artículo 9), literales a) y e), definía como un tipo de violencia contra la mujer a la económica y patrimonial respectivamente; Colombia, a través de la Ley $\mathrm{N}^{\circ} 1257$ de 2008, en su artículo $3^{\circ}$ regula el supuesto de daño patrimonial, como la "Pérdida, transformación, sustracción, destrucción, retención o distracción de objetos, instrumentos de trabajo, documentos personales, bienes, valores, derechos o económicos destinados a satisfacer las necesidades de la mujer" ${ }^{\prime \prime}$; no considera a la violencia económica.

\subsection{La violencia económica y patrimonial en la Ley $\mathrm{N}^{\circ} 30364$}

En nuestro país, la Ley para prevenir, sancionar y erradicar la violencia contra las mujeres y los integrantes del grupo familiar, Ley $\mathrm{N}^{\circ}$ 30364, publicada en el diario oficial El Peruano con fecha 23 de noviembre de 2015, de manera muy similar a la legislación argentina no define a la violencia patrimonial ni económica, ni las distingue separadamente como otras legislaciones, solo establece los supuestos de violencia económica y patrimonial en forma conjunta; así observamos que en el artículo $8^{\circ}$, literal d), la regula de la siguiente manera:

Disponible en: https://www.oas.org/dil/esp/LEY_1257_DE_2008_Colombia.pdf 
“Violencia económica o patrimonial. Es la acción u omisión que se dirige a ocasionar un menoscabo en los recursos económicos o patrimoniales de cualquier persona, a través de: 1. la perturbación de la posesión, tenencia o propiedad de sus bienes; 2. la pérdida, sustracción, destrucción, retención o apropiación indebida de objetos, instrumentos de trabajo, documentos personales, bienes, valores y derechos patrimoniales; 3. la limitación de los recursos económicos destinados a satisfacer sus necesidades o privación de los medios indispensables para vivir una vida digna; así como la evasión del cumplimiento de sus obligaciones alimentarias; 4. la limitación o control de sus ingresos, así como la percepción de un salario menor por igual tarea, dentro de un mismo lugar de trabajo".

Por su parte, el Reglamento de la citada Ley, que fuera aprobado mediante Decreto Supremo № 009-2016-MIMP, define este tipo de violencia en el numeral 7), artículo 4), de la forma siguiente: “La violencia económica o patrimonial es la acción u omisión que ocasiona daño o sufrimiento a través de menoscabar los recursos económicos o patrimoniales de las mujeres por su condición de tales o contra cualquier integrante del grupo familiar, en el marco de relaciones de poder, responsabilidad, confianza o poder, en especial contra las niñas, niños, adultos mayores o personas con discapacidad".

\section{2. ¿Cómo regula México la violencia económica y patrimonial contra la mujer?}

En México, la Ley General de Acceso de las Mujeres a una Vida Libre de Violencia, publicada el 01 de febrero de 2007, y reformada el 17 de diciembre de 2015, define separadamente a la violencia económica y a la patrimonial; así, en su artículo $6^{\circ}$, numeral III, define a la violencia patrimonial de la siguiente manera:

"Es cualquier acto u omisión que afecta la supervivencia de la víctima. Se manifiesta en: la transformación, sustracción, destrucción, retención o distracción de objetos, documentos personales, bienes y valores, derechos patrimoniales o recursos económicos destinados a satisfacer sus necesidades y puede abarcar los daños a los bienes comunes o propios de la víctima"; y en el numeral IV, se define a la violencia económica de la siguiente manera: "Es toda acción u omisión del Agresor que afecta la supervivencia económica de la víctima. Se manifiesta a través de limitaciones encaminadas a controlar el ingreso de sus percepciones económicas, así como la percepción de un salario menor por igual trabajo, dentro de un mismo centro laboral". 


\section{3. ¿Cómo se regula en Argentina la violencia económica y patrimonial contra la mujer?}

Muy similar a la nuestra, en Argentina, a través de la Ley 26.485, denominada Ley de Protección Integral para Prevenir, Sancionar y Erradicar la Violencia Contra las Mujeres, promulgada el 01 de abril de 2009, en su artículo 5, numeral 4, define y describe los supuestos en que se presenta una violencia económica y patrimonial contra la mujer.

Así, señala lo siguiente: "La que se dirige a ocasionar un menoscabo en los recursos económicos o patrimoniales de la mujer, a través de:

a) La perturbación de la posesión, tenencia o propiedad de sus bienes;

b) La pérdida, sustracción, destrucción, retención o distracción indebida de objetos, instrumentos de trabajo, documentos personales, bienes, valores y derechos patrimoniales;

c) La limitación de los recursos económicos destinados a satisfacer sus necesidades o privación de los medios indispensables para vivir una vida digna;

d) La limitación o control de sus ingresos, así como la percepción de un salario menor por igual tarea, dentro de un mismo lugar de trabajo".

Observamos que la legislación de Argentina y Perú, a diferencia de la legislación mexicana y la legislación de la República de El Salvador, no definen a la violencia económica y a la violencia patrimonial como formas distintas de violencia, no las regula como diferentes; para estas legislaciones tanto la violencia económica y patrimonial serían prácticamente lo mismo. En cambio, la legislación mexicana y la de República de El Salvador es clara en establecer y precisar cuándo estamos ante un caso de violencia económica y cuándo ante un caso de violencia patrimonial.

Como ya lo habíamos señalado, la Republica de El Salvador, mediante la Ley Especial Integral para una vida libre de violencia para las mujeres, Decreto 520, en su artículo $9^{\circ}$ hace una distinción muy clara entre violencia económica y patrimonial, así en el literal a) establece que violencia económica: "es toda acción u omisión de la persona agresora, que afecta la supervivencia económica de la mujer, la cual se manifiesta a través de actos encaminados a limitar, controlar o impedir el ingreso de sus percepciones económicas"; y en su literal e) define a la violencia patrimonial de la siguiente manera: "Son las acciones, omisiones o conductas que afectan la libre disposición del 
patrimonio de la mujer; incluyéndose los daños a los bienes comunes o propios mediante la transformación, sustracción, destrucción, distracción, daño, pérdida, limitación, retención de objetos, documentos personales, bienes, valores y derechos patrimoniales. En consecuencia, serán nulos los actos de alzamiento, simulación de enajenación de los bienes muebles o inmuebles; cualquiera que sea el régimen patrimonial del matrimonio, incluyéndose el de la unión no matrimonial". Observamos incluso en este caso que la misma norma declara la nulidad de los actos por los cuales se realizará alzamineto, simulación de enajenación de los bienes muebles o inmuebles; cualquiera que sea el régimen patrimonial del matrimonio, incluyéndose el de la unión no matrimonial.

\section{LA VIOLENCIA ECONÓMICA Y PATRIMONIAL COMO DOS TIPOS DE VIOLENCIA QUE AFECTAN A LAS MUJERES DE DISTINTAS FORMAS}

¿Son diferentes los dos tipos de violencia : la violencia económica y patrimonial? Sí, son dos tipos diferentes de violencia.

¿Cuándo estamos ante un caso de violencia económica? Para saber con claridad cuándo estamos ante un caso de violencia económica, resulta interesante tener en consideración la definición que sobre este tipo de violencia hace la legislación mexicana a través de la "Ley General de Acceso de las mujeres a una vida libre de violencia", referida líneas arriba. En dicha disposición normativa se establece que la violencia económica "se manifiesta a través de limitaciones encaminadas a controlar el ingreso de las percepciones económicas de la víctima (esto dentro del ámbito familiar), así como la percepción de un salario menor por igual trabajo (esto dentro de un ámbito laboral)". En este mismo sentido, observamos que El Salvador a través de la "Ley Especial para una vida libre de violencia para las mujeres- Decreto 520" establece, en su artículo $9^{\circ}$ que este tipo de violencia se manifiesta a través de actos encaminados a limitar, controlar o impedir el ingreso de sus percepciones económicas de la mujer.

De lo anterior se extrae como conclusión que la violencia económica tiene como característica singular la limitación, control e impedimento de las percepciones o ingresos económicos de la mujer, violencia que se ejerce por el agresor con la finalidad de hacer dependiente económicamente a la víctima y hacerla más vulnerable. En este sentido, también se ha definido sucintamente a la violencia económica como: "una serie de mecanismos de control y vigilancia sobre el comportamiento de las mujeres con relación al uso y distribución del dinero, junto con la amenaza constante de no proveer recursos económicos" (Medina, 2013, p. 107). 
¿Cuándo estamos frente a un caso de violencia patrimonial? Con respecto a la violencia patrimonial, hemos de tener también en cuenta lo que establece la legislación mexicana, así el precitado artículo $6^{\circ}$, numeral III, de la "Ley General de Acceso de las mujeres a una vida libre de violencia", señala que este tipo de violencia se manifiesta en la transformación, sustracción, destrucción, retención o distracción de objetos, documentos personales, bienes y valores, derechos patrimoniales o recursos económicos destinados a satisfacer sus necesidades y puede abarcar los daños a los bienes comunes o propios de la víctima. Lo que concuerda con la definición dada por la Ley Especial Integral para una vida libre de violencia para las mujeres, Decreto 520, de la Republica de El Salvador, que la define en su artículo $9^{\circ}$ literal e), como las acciones, omisiones o conductas que afectan la libre disposición del patrimonio de la mujer; incluyéndose “... sustracción, destrucción, distracción, daño, pérdida, limitación, retención de objetos, documentos personales, bienes, valores y derechos patrimoniales".

A esta definición, le agregaríamos una precisión importante hecha por la legislación panameña a través de la Ley $\mathrm{N}^{\circ} 38$ del 10 de julio de 2001, denominada: "Ley que reforma y adiciona artículos al Código Penal y Judicial, sobre violencia doméstica y maltrato al niño, niña y adolescente ${ }^{\prime \prime}$, que en la parte final del numeral 10 del artículo $2^{\circ}$, dice que:"también será considerada como violencia patrimonial la limitación injustificada al acceso y manejo de bienes comunes".

Por tanto, de lo anterior podemos extraer como conclusión que se configura la violencia patrimonial contra la mujer cuando se le priva, limita, restringe o despoja injustificadamente de cualquier bien patrimonial (sea este común o propio de la víctima) por parte del agresor; es decir, no solo será violencia patrimonial cuando se le sustrae, destruye, retiene o perturba la posesión de bienes o derechos patrimoniales de la víctima, sino también cuando no se le deja participar en la disposición o conducción de dichos bienes.

Entonces, podemos observar que la violencia económica y patrimonial son dos tipos de violencia que se configuran de forma distinta, que tienen supuestos de hechos distintos. En este sentido, se ha señalado que este tipo de violencia (patrimonial) podría confundirse con la económica. Sin embargo, por un lado observamos que la violencia económica se basa en que el agresor, por ejemplo, limita e impide que la víctima acceda al dinero o a los recursos económicos; es decir, no aporta de forma intencional el dinero

Recuperado de : http://www.sipi.siteal.iipe.unesco.org/normativas/157/ley-ndeg-382001-ley-que-reforma-y-adiciona-articulos-al-codigo-penal-y-judicial-sobre. 
para atender necesidades básicas del hogar y/o sus hijos, ni para mantener la casa, mientras que la violencia patrimonial se configura, por ejemplo, cuando el agresor vende objetos de la mujer para conseguir dinero para él, le rompe o esconde objetos de valor o documentos personales (DNI, pasaporte, partida de nacimiento entre otros). Un ejemplo sería si la mujer quiere irse de vacaciones con sus amigas y él no está de acuerdo, pero ella decide obviar su negación e irse; entonces, él le esconde su pasaporte y el dinero que tenía planeado llevarse al viaje (Aranda, 2015).

\section{SUPUESTOS DE VIOLENCIA ECONÓMICA Y PATRIMONIAL CONTRA LA VÍCTIMA SEGÚN NUESTRA LEY Nº 30364}

De acuerdo con las definiciones ya establecidas sobre estos dos tipos de violencia contra la mujer y hechas las diferencias existentes entre ellas, podemos ahora hacer la disquisición del artículo $8^{\circ}$, literal d), de la Ley $\mathrm{N}^{\circ} 30364$ a efectos de verificar los supuestos de violencia económica y patrimonial que regula.

Así conforme con nuestra ley, serían casos típicos de violencia económica lo supuestos establecidos en los inciso 3 y 4 que señalan respectivamente lo siguiente: “3. la limitación de los recursos económicos destinados a satisfacer sus necesidades o privación de los medios indispensables para vivir una vida digna; así como la evasión del cumplimiento de sus obligaciones alimentarias"; "4. la limitación o control de sus ingresos, así como la percepción de un salario menor por igual tarea, dentro de un mismo lugar de trabajo".

De otro lado, serían casos tipo de violencia patrimonial los supuestos establecidos en los numerales 1 y 2 del citado literal $d$ ), que señalan respectivamente lo siguiente: "1. la perturbación de la posesión, tenencia o propiedad de sus bienes; 2. la pérdida, sustracción, destrucción, retención o apropiación indebida de objetos, instrumentos de trabajo, documentos personales, bienes, valores y derechos patrimoniales".

\section{CASOS TÍPICOS DE VIOLENCIA ECONÓMICA DENTRO DEL ÁMBITO FAMILIAR} familiar?

¿Cómo se presenta o acontece la violencia económica en el ámbito

Veamos a continuación solo algunos casos de testimonios reales de mujeres que han sido objeto de violencia económica: 
1. "Gabriela se casó muy joven, dejó la preparatoria y se dedicó por completo a su hogar. Ahora tiene 25 años, dos hijos y un marido con quien, confiesa, no es feliz. Señala que: 'Jamás me ha pegado, pero me controla en todo, siempre me pide cuentas sobre lo que gasto y ... me hace sentir muy mal" (Vaca, 2011).

2. "En casa nunca falta nada. El gasto llega puntual, las colegiaturas de los hijos se pagan a tiempo, la despensa siempre está llena... pero todo es de él. Él toma todas las decisiones de los que se compra para la familia. Dice que 'el que paga manda'. Yo no puedo escoger el sabor del yogurt" (Meza, 2017).

3. "Recibí una llamada en mi programa de radio de Aurelia, quien enviudó y se enteró de una terrible verdad tras 27 años de matrimonio: no que el difunto tuviera una amante, hijos con otra o que fuera un espía ruso - pero sí descubrió que había sido víctima de abuso económico, algo que es considerado violencia doméstica. Cuando su esposo murió, esta mujer no tenía idea de cuánto dinero tenían en el banco, cuánto debían en la casa y ni siquiera sabía firmar un cheque. Su marido nunca le permitió tener acceso al dinero del hogar y siempre usó las finanzas como una forma de ejercer poder y control sobre ella" (Marín, 2011).

Estos testimonios son casos típicos de violencia económica ejercida contra la mujer. A continuación veremos supuestos típicos de violencia económica dentro del ámbito familiar que padece la mujer como parte débil muchas veces de la relación de pareja. Sin ser los únicos, ni pretender mostrar una lista exhaustiva, presentamos a continuación los siguientes supuestos que se pueden tomar como ejemplos:

1. El agresor no permite que la mujer tenga un trabajo fuera de casa y por tanto, hace que dependa económicamente de él. El agresor obliga a su pareja a dejar de trabajar; precisamente, una característica que se observa en este tipo de violencia es que el agresor suele establecer un mecanismo de "bloqueos" económicos haciendo que la víctima no tenga los recursos económicos necesarios como para abandonar la relación.

2. El agresor no permite que la víctima estudie o tome algún curso o capacitación, no le permite desarrollarse profesionalmente.

3. El agresor se niega a cumplir económicamente con los gastos del hogar. El agresor se niega a pagar su parte en los gastos básicos de la casa como por ejemplo agua, luz, teléfono, internet, cable, gas, etc., y los mismos terminan recayendo sobre su pareja, la víctima. 
4. El incumplimiento de la obligación de contribuir con la alimentación de los hijos o la falta de pago de la pensión de alimentos. Con respecto a este supuesto, que ya se encuentra específicamente regulado en nuestra legislación ${ }^{6}$, se ha argumentado que la omisión del pago de la cuota alimentaria por parte del progenitor, no solo afecta al menor, sino también perjudica con gravedad a la denunciante, ya que debe proveerse y proveer al hijo en común de todo lo necesario para satisfacer sus necesidades. De modo que la obligación alimentaria si bien se funda en las necesidades de los hijos, tiene también una afectación directa sobre la economía y los derechos de la mujer" (Radom, 2016).

En consecuencia, el no aportar dinero intencionalmente para atender las necesidades de los hijos menores de edad o mayores que estén estudiando, así como para la manutención de la casa (agua, luz, gas etc.), también constituye un acto de violencia económica contra la mujer.

5. Cuando el agresor reclama constantemente a la víctima por la forma en que ha gastado y cómo ha gastado el dinero que le ha dado para la semana. En este caso, la víctima debe dar justificación constante de aquello que ha gastado, en dónde ha gastado el dinero y en qué. La víctima no dispone del presupuesto con libertad; se siente constantemente presionada y vulnerada en su autoestima personal.

6. Cuando el agresor no valora y menosprecia el trabajo que hace su pareja como ama de casa, infravalora su papel y no le permite proyectarse a nivel profesional.

7. El agresor amenaza constantemente a la víctima con botarla de la casa sin ningún tipo de medio económico.

8. El agresor no deja participar a la víctima en las decisiones económicas del hogar, y si trabaja, debe aportar todo el dinero para que el agresor lo administre. "El agresor le hace creer a la mujer que sin él ella no podría ni siquiera comer. Su pareja es quien controla los gastos" (Diez, 2012.) En este supuesto se ha argumentado lo siguiente: "si el esposo controla las finanzas familiares, y solo entrega una pequeña cantidad de dinero a la esposa para las necesidades del hogar de forma semanal, no existe igualdad de condiciones entre el esposo y la esposa, por tanto, estamos frente a un acto de violencia familiar del tipo económico". (García, 2014).

Artículo $8^{\circ}$, literal d), numeral 4, "la evasión del cumplimiento de sus obligaciones alimentarias". 
9. "Negarle el dinero suficiente para que satisfaga sus necesidades elementales, tales como comer, vestirse, tener actividades de recreación, etc.". (Diez, 2012.)

10. No aportar el dinero intencionalmente para atender las necesidades básicas (salud, educación y alimentación) tanto de la víctima como de los hijos menores de edad, así como los gastos de la casa (agua, luz, gas, teléfono).

\section{SUPUESTOS DE VIOLENCIA PATRIMONIAL CONTRA LA MUJER DENTRO DEL ÁMBITO FAMILIAR}

A continuación, señalaremos algunos supuestos típicos que constituyen violencia patrimonial contra la mujer dentro del ámbito familiar:

1. Quitarle el celular, romper, esconder, robar o vender sin su permiso sus objetos devalor (televisor, radio, celular, joyas, etc.) asícomo sus documentos personales (acta de nacimiento, documento deidentidad, pasaporte, carnet, tarjetas de crédito).Actos del agresor que menoscaben, limiten o restrinjan la libre disposición de los bienes o derechos patrimoniales de la mujer.

2. Cuando el agresor destruye $\mathrm{u}$ oculta documentos de dominio o de identificación personalobienes, diplomas, objetos personales, instrumentos de trabajo, libros que le sean indispensables para ejecutar sus actividades habituales.Elagresordañalosbienesopertenenciasdesupareja,comoropau objetos personales de valor, con elobjetivode humillarla ohacerla sentirmal.

3. Actos del agresor que obliguen a la víctima a suscribir documentos que afecten,limiten,restrinjansupatrimoniooloponganenriesgo;oqueloeximan de responsabilidad económica, penal, civil o de cualquier otra naturaleza.

4. El agresor extrae el dinero de la cuenta bancaria de su pareja sin su consentimiento o cuando el abusador induce a la víctima para abrir una cuenta conjunta donde se deposita el sueldo de esta y luego retira todo el dinero que se va acreditando.

5. El agresor solicita créditos al banco a nombre de su pareja (la víctima), persuaden a esta para solicitar créditos a su nombre prometiendo que luego cumplirán con los pagos; sin embargo, se ha detectado que solo pagan las primeras cuotas y dejan luego dejan de pagar, dañando el perfil crediticio de su pareja. 


\section{IMPORTANCIA DE ERRADICAR LA VIOLENCIA ECONÓMICA Y PATRIMONIAL CONTRA LA MUJER}

¿Y por qué es importante hablar de violencia económica y patrimonial? Si bien nuestra Ley $\mathrm{N}^{\circ} 30364$, en el artículo 8, literal d), define a la violencia económica o patrimonial como la "acción u omisión que se dirige a ocasionar un menoscabo en los recursos económicos o patrimoniales de cualquier persona", el daño que ocasiona en la víctima va mucho más allá que lo simple económico y /o patrimonial.

En efecto, la violencia contra la mujer en cualquiera de sus formas es un acto de discriminación y constituye un acto de violación de los derechos humanos. Con mayor razón cuando esta forma de violencia tiene su origen en el control económico del hombre sobre la mujer, limitándole, restringiéndole y no permitiendo que ella tenga algún control sobre sus ingresos o sobre sus propios bienes, hecho que, indudablemente, genera una desvalorización en su autoestima, generándole un daño psicológico grande cuando esto es repetitivo en el tiempo y no es detectada ni denunciada en su debida oportunidad. Por ello, constituye una gran tarea de los operadores de justicia de sancionar y dictar las medidas de protección adecuadas frente a este tipo de violencia contra la mujer. También es una gran tarea de la Policía Nacional y del Ministerio de la Mujer de coadyuvar a las víctimas en formalizar las denuncias correspondientes cuando tengan noticia de este tipo de violencia. Asimismo, las víctimas tienen el deber y el derecho de denunciar cualquier acto que afecte su supervivencia económica y/o patrimonial causado por su pareja; esto es, denunciando cualquier acto que implique la transformación, sustracción, destrucción, retención o distracción de objetos, documentos personales, bienes y valores, derechos patrimoniales o recursos económicos destinados a satisfacer sus necesidades; y denunciar toda acción u omisión del agresor que limite, restrinja o controlar sus ingresos de sus percepciones económicas.

La violencia económica y patrimonial en nuestra legislación es un tipo de violencia nueva, pues, antes solo se consideraba como violencia la física, sexual y psicológica. Incluso actualmente, en algunos países de la región como Chile y Venezuela hasta la fecha no la consideración en su legislación como un tipo de violencia contra la mujer.

En la violencia económica y patrimonial, el agresor usa el poder económico para provocar un daño a su pareja, aprovecha su ventaja económica; por ello, no permite que su víctima trabaje fuera del hogar o genere sus propios ingresos; las víctimas son privadas o tienen muy restringido el 
manejo del dinero y la administración de los bienes, con lo que se crea una situación de estrés en la familia, relacionado con los ingresos económicos. Del mismo modo, el agresor busca evitar que la mujer tenga acceso a los bienes muebles e inmuebles que por vínculo matrimonial o de hecho ella tiene derecho y le pertenecen. Así, muchas veces el hombre pone los bienes a nombre de otra persona como forma de esconderlos o los retiene de manera arbitraria (Diez, 2014).

El agresor siempre va a intentar que la víctima no pueda acceder al dinero, no pueda generar sus propios ingresos, ello con la finalidad de hacerla dependiente de él. En este sentido se señala que "Al marcar la desigualdad en el acceso al dinero, se atenta directamente contra la autonomía y libertad de la mujer" (Díaz, 2014).

Esta situación es muy común, muchas veces ocurre que la víctima no denuncia cuando está siendo objeto de violencia económica o patrimonial, tal vez en la creencia que este tipo de agresiones no constituyen violencia familiar o piensa que no tendría amparo legal; o porque cuando acudió a una institución estatal a interponer su denuncia no le recibieron por considerar que los hechos no constituyen violencia familiar. En este sentido, se ha advertido que: "Lo cierto es que la violencia económica opera de forma sutil y muchas veces solapada para las personas involucradas, como así también para los funcionarios que deben tomar decisiones. Por ello, es fundamental que para dar un correcto abordaje, los operadores jurídicos tengan capacitación y una mirada sensibilizada para no reproducir perjuicios o prácticas estereotipadas que generen revictimización y mantengan las relaciones desiguales de poder" (Radom, 2016). Lo mismo ocurre con el abuso patrimonial, "el abuso patrimonial suele darse de manera gradual. El dominador, que conoce el discurso políticamente correcto, se comportará adecuadamente hasta que sienta que su víctima está vulnerada y a partir de allí, irá exigiendo que la mujer renuncie a relaciones, al ejercicio de la profesión y al trabajo fuera de casa" (Díaz, 2014).

Si se denunciase oportunamente la violencia económica y se dictasen las medidas de protección adecuadas, podría disminuirse la violencia física y la psicológica; puesto que, muchas veces, la violencia física y psicológica tiene su origen en la violencia económica. Es muy probable que una violencia económica desencadene en una violencia psicológica y física. En efecto, el reclamo constante sobre cómo gastan el dinero de la semana, la prohibición para trabajar o estudiar, la acusación de que la pareja se ha gastado el dinero destinado al hogar, puede generar daño psicológico a la víctima o cuándo esta reaccione sufra algún daño físico por el agresor. Algunos han señalado 
inclusive, que la violencia económica nos remite al ejercicio de la violencia psicológica "la violencia económica, remite al ejercicio de la violencia psicológica, pues pretende aniquilar la independencia de la mujer y dañar su autoestima y estabilidad emocional y afectiva" (Benítez, 2004, p. 44).

Un hecho que nos puede revelar que las denuncias por violencia económica o patrimonial no se formalizan por parte de la víctima es la estadística realizada, en el primer trimestre del 2017, por el Programa Nacional contra la Violencia Familiar y Sexual (Pncvfs) del Ministerio de la Mujer y Poblaciones Vulnerables (MIMP) ${ }^{7}$, en cuyo boletín informativo señala que del total de denuncias por violencia familiar que recibieron en ese periodo, 3,363 denuncias se hicieron por violencia psicológica; 1,979 se hicieron por violencia física; 664 denuncias por violencia sexual y tan solo 18 denuncias por violencia económica y/o patrimonial. Esto no debe interpretarse en el sentido de que el índice de violencia económica y/o patrimonial sea muy escaso, lo que debemos interpretar más bien es que este tipo de violencia no está siendo denunciada por la víctima ya sea por falta de conocimiento de que dichas agresiones también constituyen violencia familiar o porque sus denuncias no están siendo recibidas.

\section{CONCLUSIONES}

1. La violencia económica y patrimonial afecta la autoestima de la víctima, por cuanto la limita en el ejercicio de sus derechos, la desvaloriza, la humilla y transgrede su derecho fundamental a la subsistencia que toda persona debe gozar dignamente. Circunscribe a la víctima al nivel de la supe rvivencia. Este tipo de violencia resulta ser mucho más habitual para la mayoría de mujeres en el ámbito familiar.

2. La violencia económica y patrimonial es un tipo de violencia (ejercida generalmente contra la mujer) que empieza de manera imperceptible, que es aceptada al principio muchas veces por la víctima de buena fe o por temor; sin embargo, esto que empieza como algo aceptable e inadvertido se va tornando de a poco cada vez más agraviante a tal punto que el agresor llega a "asfixiar" a la víctima quien solo denuncia cuando es víctima de violencia física o psicológica.

3. Se debe detectar, denunciar y sancionar oportunamente cualquier acto de violencia patrimonial y/o económica contra la mujer a efectos de que no escale en una violencia física, psicológica ni sexual; para ello, se requiere mayor difusión respecto de este tipo de violencia para

http://www.mimp.gob.pe/contigo/ 
que la víctima conozca que sí puede denunciar este tipo de violencia y que puede recibir una medida de protección adecuada y oportuna.

4. Los actos de violencia económica y patrimonial, produce en las víctimas efectos desfavorables en su autoestima y autonomía para tomar decisiones, lo que puede propiciar que sea vulnerable para ser víctima de otros tipos de violencia como la física, psicológica y sexual.

\section{REFERENCIAS}

Aranda, Noelia (15 de abril de 2015). ¿Y si no sé que soy víctima? Tipos de violencia de género e indicadores prácticos para detectar la violencia psicológica. Criminología y Justicia. Recuperado de: https://cj-worldnews. com/spain/index.php/es/criminologia-30/violencia-de-genero/item/2869

Benítez Jiménez, María José (2004). Violencia contra la mujer en el ámbito familiar, cambios sociales y legislativos. Madrid, España : Editorial EDISOFER S.L.

Díaz Virzi, Sabrina (21 de noviembre de 2011). Violencia es más que pegar: cuando el abuso es económico. Clarin. 21/11. Recuperado de: https://www. clarin.com/genero/dinero-genero-trabajo-violencia-violencia de generoeconomia-mujer_0_BJuPI5KP7g.html.

Diez, Sara (21 de febrero de 2012). Violencia económica: delito machista encubierto. Mujer sin cadenas. Recuperado de: https://mujersincadenas. blogspot.pe/2012/02/violencia-economica-delito-machista.html.

Diez, Sara (2014).Violencia económica: arma de dominación y control. Mujer AF. Recuperado de: http://www.mujeraf.com/2014/01/violencia-economicaarma-de-dominacion-y-control).

García, Emilia (25 de diciembre de 2014). 4 formas financieras de violencia intrafamiliar y por qué nunca deberías entregar tu independencia económica. Recuperado de: http:/ / www.upsocl.com

Marín, María (19 de noviembre de 2011). ¿Eres víctima del abuso económico? Recuperado de: http://www.mariamarin.com/eres-victima-del-abusoeconomico/.

Medina, Graciela (2013). Violencia de género y violencia doméstica. Sante Fe, Argentina : Editorial Rubinzal Culzoni. Pág. 107. Diciembre. 
Meza Escorza, Tania (07 de febrero de 2017). La violencia económica y patrimonial contra las mujeres.

Recuperado de: http://www.milenio.com/firmas/tania meza_escorza/ violencia-economica-patrimonial-mujeres_18_898890136.html.

Núñez,Roselía (2009) La violencia económica hacia las mujeres es una realidad. ATENEA, Centros de Estudios de Género Universidad de El Salvador. Año 2. Revista 4. Ciudad Universitaria. Noviembre 2009. El Salvador.

Radom, Sofía (07 de diciembre de 2016). Violencia económica contra las mujeres: perspectiva de género en la adopción de medidas judiciales. Thomson Reuters.

Recuperado de: http://thomsonreuterslatam.com/2017/03/violenciaeconomica-contra-las-mujeres-perspectiva-de-genero-en-la-adopcion-demedidas-judiciales.

Truffello, Paola (22 de octubre de 2010). Violencia patrimonial como un tipo de violencia intrafamiliar Biblioteca del Congreso Nacional de Chile. Recuperado de: https://www.camara.cl/camara/media/seminarios/violencia/bcn 2.pdf.

Vaca Prieto, Grisel (07 de noviembre de 2011). Detecta la violencia económica. El Diario NY . Recuperado de: https://eldiariony.com/2011/11/07/detectala-violencia-economica

Fecha de recepción: 31 de agosto de 2017

Fecha de aceptación: 15 de setiembre de 2017 